\title{
Role models, radicals, and reactionaries
}

Much of the detail of what I learned at medical school I have subsequently forgotten. I suspect this is not a unique observation. The useful stuff is gradually synthesised, reinforced and one day applied to the patient in front of you. The rest falls away with time. However, there is another more subtle yet powerful influence that remains to this day.

One of the biggest influences on my career has been and continues to be, the role model. Often, it must be said, these experiences were negative - the surgeon who swore and threw implements around the theatre or the punctilious consultant who deliberately tried to catch out students. Yet a few were positive and these left a lasting impression with me. On rare occasions, these were the people who made you go home at night thinking 'this is the kind of thing I want to do' or perhaps 'this is the kind of person I want to be'. There is some evidence that such encounters may affect others career intentions too. ${ }^{1,2}$

Medical education is at the mercy of the same trends, idiosyncrasies, and fashions as any other academic activity. Nevertheless, in general practice at least, the role of mentorship as the cornerstone of teaching and learning remains unchanged over several generations. Students may now have e-portfolios and PDPs to worry about but much of their learning is still the result of sitting in with a doctor or a nurse; watching, listening, practising and debating with each clinical encounter. Much of this learning is never written down and is part of the 'hidden curriculum' that may either challenge or affirm students' attitudes, prejudices, and perceptions.

For me, role models aren't necessarily people. They could be a type of job, the way a group works together or even the wider environment where work takes place. Any of these could inspire or deter a trainee on a particular path. The diversity of general practice is perhaps one of its greatest strengths. Whereas the experience of a student in a hospital may be relatively homogenous, general practices and the communities of which they are a part, are comprised of very different kinds of people responding to different problems in different ways.

We are used to being self-aware in considering how we appear to patients and staff - the communication skills we deploy and the 'games we play'. But consider for a moment how we may seem to students watching our every move as an impressionable observer. Do they see someone who is preoccupied with targets, data collection and impenetrable funding streams? Do they see someone who is emotionally neutral? Or tired? Or angry? Or cynical? Or perhaps they see someone who is inquisitive? Or compassionate? Or perhaps even serene? Do they see someone who still retains some of the passion that they took with them to medical school?

One wonders just how radical or confrontational the student experience in general practice is today. The delivery of care, the medical workforce, and medical training have all become increasingly micromanaged. Does this mean that students are less likely to be challenged to question what may now be accepted norms? As a profession, do we have an obligation to produce a cohort of graduates who can passively fit in with the values of modern service provision or one that should question and challenge those values?

It is inevitable that the experience of studying medicine in a leafy college town is different from studying in a metropolis. Yet there may be other role models out there in the community that students could learn from. We should consider how imaginative we can be in terms of the people, places, and situations that we direct students towards. This should include exposure to the neglected, chaotic, and the disenfranchised among our society as well as to those sectors which are easier to engage with. ${ }^{3}$
Perhaps above all, we should recall the enthusiasm and passion that we had at the outset and which we hopefully still retain despite the mortgage and the politics. We should remember what it was like to watch others at work and remember that one day they will be sitting in the other seat with someone watching them. And we should look forward too. There is always the potential to be inspired by someone or something which is one step ahead of you on your own journey.

\section{Keith Taylor}

\section{Author's Note}

A student's viewpoint follows on page 878 (DOI: 10.3399/bjgp09X473024).

\section{REFERENCES}

1. Sinclair HK, Ritchie LD, Lee AJ. A future career in general practice? A longitudinal study of medical students and pre-registration house officers. Eur J Gen Pract 2006; 12(3): 120-127.

2. Howe A, Ives G. Does community-based experience alter career preference? New evidence from a prospective longitudinal cohort study of undergraduate medical students. Med Educ 2001; 35 391-397.

3. Littlewood S, Ypinazar V, Margolis SA, et al. Early practical experience and the social responsiveness of clinical education: systematic review. BMJ 2005; 331: 387-391.

DOI: 10.3399/bjgp09X473015 